\title{
Glass Microbeads in Analog Models of Thrust Wedges
}

\author{
TAYNARA D'ANGELO and CAROLINE J.S. GOMES \\ Universidade Federal de Ouro Preto, Departamento de Geologia, Campus \\ Morro do Cruzeiro, s/n, 35400-000 Ouro Preto, MG, Brazil \\ Manuscript received on May 17, 2016; accepted for publication on September 8, 2016
}

\begin{abstract}
Glass microbeads are frequently used in analog physical modeling to simulate weak detachment zones but have been neglected in models of thrust wedges. Microbeads differ from quartz sand in grain shape and in low angle of internal friction. In this study, we compared the structural characteristics of microbeads and sand wedges. To obtain a better picture of their mechanical behavior, we determined the physical and frictional properties of microbeads using polarizing and scanning electron microscopy and ring-shear tests, respectively. We built shortening experiments with different basal frictions and measured the thickness, slope and length of the wedges and also the fault spacings. All the microbeads experiments revealed wedge geometries that were consistent with previous studies that have been performed with sand. However, the deformation features in the microbeads shortened over low to intermediate basal frictions were slightly different. Microbeads produced different fault geometries than sand as well as a different grain flow. In addition, they produced slip on minor faults, which was associated with distributed deformation and gave the microbeads wedges the appearance of disharmonic folds. We concluded that the glass microbeads may be used to simulate relatively competent rocks, like carbonates, which may be characterized by small-scale deformation features.
\end{abstract}

Key words: compressional deformation models, sand, microbeads, physical and frictional characterizations.

\section{INTRODUCTION}

Several granular materials other than quartz sand have been employed to simulate compressive wedges under natural gravity conditions in analog models. These materials include wet clay (e.g., Eisenstadt and Sims 2005, Withjack et al. 2007), glass microbeads, aluminum microspheres (Rossi and Storti 2003), water-saturated granular materials (Graveleau et al. 2011), siliceous powder (Bonnet et al. 2007), hemihydrate powder ( $\mathrm{CaSO} 4 \cdot 1 / 2 \mathrm{H} 2 \mathrm{O})$

Correspondence to: Taynara D'Angelo

E-mail: taynaradangelo@hotmail.com (van Gent et al. 2010), and a sand-mica mixture (Gomes 2013). Glass microbeads are commonly used to represent incompetent layers (e.g., mudstone, shale or a layer of high fluid pressure) between competent layers when simulating a multilayered rock package (e.g., Teixell and Koyi 2003, Panien et al. 2005, 2006b, Ravaglia et al. 2006) or a low-friction detachment (e.g., Turrini et al. 2001, Massoli et al. 2006, Malavieille 2010, Konstantinovskaya and Malavieille 2011). Glass microbeads constitute a granular material that obeys the Mohr-Coulomb criterion of failure and presents the nonlinear brittle deformation behavior of crustal 
rocks. Glass microbeads are similar to sand but are mechanically weaker. Viscous silicone putties are also used to replicate ductile detachments; however, this material simulates a much lower strength, such as those that are commonly produced in evaporate layers.

Teixell and Koyi (2003) used various combinations layers of sand, glass microbeads, and mixtures of sand and microbeads to investigate the effects of the mechanical stratigraphy on thrustrelated deformation. The authors concluded that 1) the sand and microbeads experienced layer-parallel shortening, although these materials differed in their packing properties: sand accommodated this shortening by compaction, whereas glass microbeads did so by layer thickening; 2) compositional contrasts influenced partitioning between fault imbrication and folding, with the latter being more common in microbeads layers; and 3) a weak detachment layer enhanced the mechanical contrasts between different layers. Massoli et al. (2006) also investigated experimental multilayered rock packages in a thrust system by focusing on the problem of multiple detachments. Two weak microbeads layers were introduced into a sand pile, one at the base and the other in the middle of the model. In their models, the microbeads layers produced a strong decoupling effect that created different sets of structures above each detachment. However, the overall structural evolution depended on the larger structures that detached at the deeper detachment. Panien et al. (2006b) used glass microbeads and sand in inversion experiments (analog and numerical). The authors showed that the mechanical properties of the basin fill and the basal friction are two important factors that control inversion. An entire weak basin fill as well as one weak basin layer strongly controlled the location and orientation of fore- and back-thrusts. In addition, weak basal friction increased the transmission of shortening to the basin. Using analog and numerical models, Yamada et al. (2006) compared the deformation of a pure sand model with that of sand model that incorporated a weak glass microbeads layer as the basal detachment. These models confirmed the general rules of the critical taper theory as widely discussed by other analog modelers.

We analyze the structural evolution of compressional wedges consisting entirely of microbeads. First, we obtain a better picture of the mechanical behavior of glass microbeads for analog modelling; we intend to investigate how weak microbeads, which have not previously been used in the experimental modeling of a whole tectonic system, can accommodate shortening in a compressional wedge. Second, we discuss whether this deformation is suitable to simulate the shortening of rock sequences.

This paper presents two series of analog experiments for comparison. We employed glass microbeads in the Series 1 models, whereas Series 2 contained quartz sand. To obtain a wideranging deformation for the two analog materials, we performed analog experiments that overlie detachments with three different basal frictions, which influence the evolution of the thrust wedges. We varied the basal substrates in the models by using sheets of cards and plastic, a layer of microbead under the sand pack and a layer of sand under the microbeads pack (Fig. 1a). The basal layers were introduced to rigorously apply the same angle of basal friction for microbeads and sand. In one experiment, we analyzed the effect of basal microbeads thickness on the deformation.

The experiments began with a compositional and physical characterization (density, grain texture, size and aspect ratio) of the microbeads and sand, followed by an analysis of the frictional properties of the two analog materials.

\section{ANALOG MATERIALS}

\section{COMPOSITION AND PHYSICAL CHARACTERISTICS}

We used artificial glass microbeads with a grain size that was described by the supplier as between 0.18 


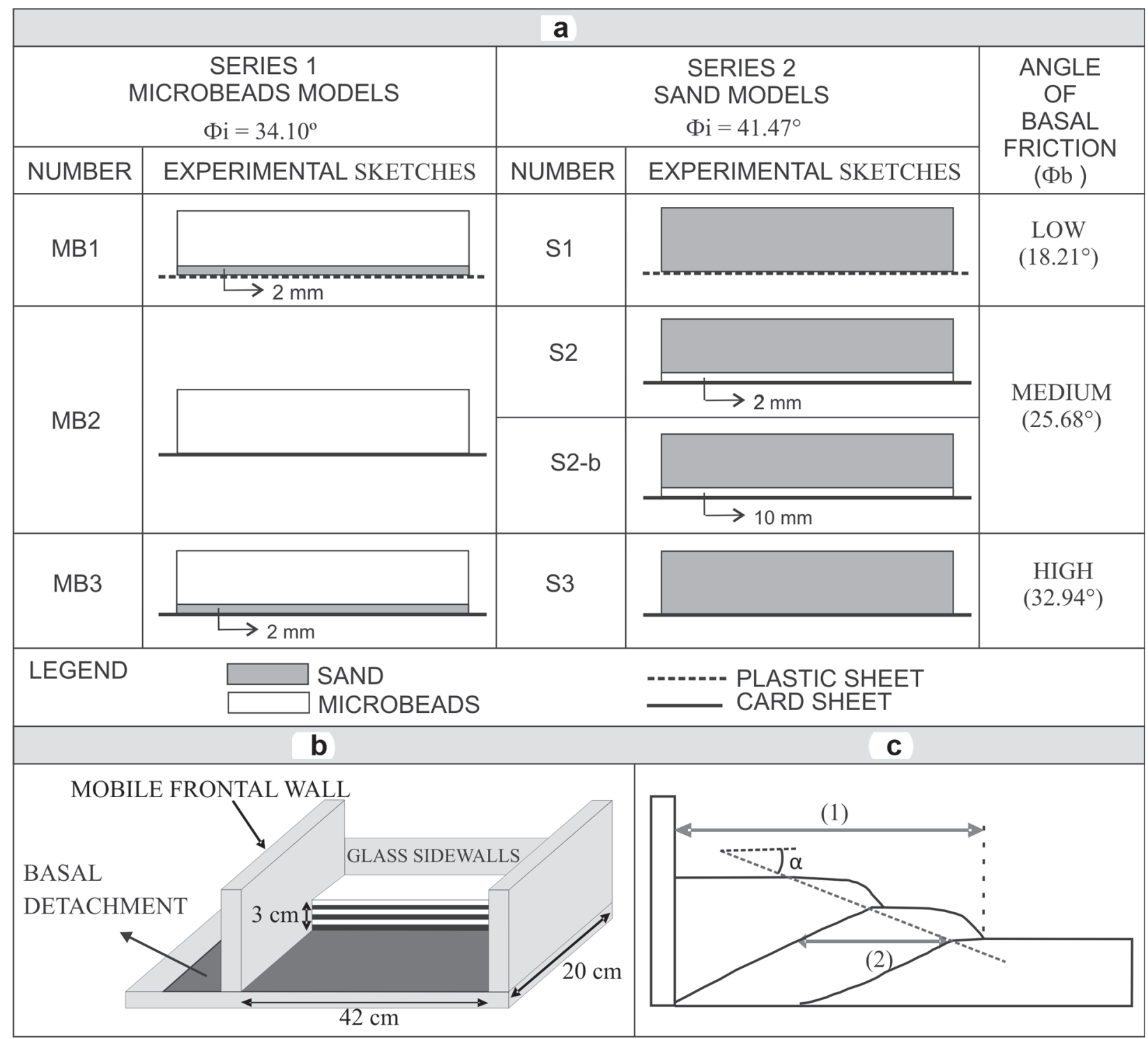

Figure 1 - a) The analog models with respective substrates and frictional properties. $\phi_{\mathrm{i}}=$ angle of internal friction; $\phi_{\mathrm{b}}=$ angle of basal friction; $\mathrm{MB}=$ microbeads; $\mathrm{S}=$ sand. b) The experimental box with model dimensions. c) Cross-section showing how the fault spacing and wedge slope angle and length were measured. (1) Length of the compressive wedge, (2) spacing between the faults, and $(\alpha)$ slope angle of the compressive wedge.

and $0.30 \mathrm{~mm}$ and a natural sand that was sieved between 0.21 and $0.35 \mathrm{~mm}$. Energy dispersive $\mathrm{X}$-ray spectroscopy (EDX) with a scanning electron microscope (SEM) determined that the chemical composition of the artificial glass microbeads was 78.2\% $\mathrm{SiO} 2,12.84 \% \mathrm{Na} 2 \mathrm{O}$, and $2.30 \% \mathrm{MgO} \pm$ other material. Glue-impregnated thin sections of the granular materials, which were examined under a polarizing microscope, showed that the sand was composed of $90 \%$ quartz, $7 \%$ feldspar and 3\% accessories.

Electron backscattering secondary (EBS) digital images were used to determine the grain shapes both descriptively (surface texture and roundness) and quantitatively (aspect ratio; Table I). The microbeads have smooth grain surfaces, and the sand grains have irregular surfaces, which are commonly characterized by conchoidal fractures. 
A visual comparison of the grains with the standard images of the Powers (1953) classification described the microbeads particles as well-rounded to sub-rounded and the sand grains as angular. The grain shapes were quantified by measuring the major and minor diameters of 100 grains using the Image SXM (1.92 version) and Microsoft Excel 2010 software to calculate the aspect ratio. The ratios were slightly surprising. The microbeads had an aspect ratio of 1.31 , which was not as spherical as expected. However, the aspect ratio of the sand grains was 1.58 , which revealed that these grains were substantially more elongated than the microbeads.

To determine the bulk density of the analog materials, we measured the mass of a known volume in a precision balance with a sensitivity of $0.01 \mathrm{~g}$. The measurements were conducted by sifting the granular material through a $0.35 \mathrm{~mm}$ mesh sieve from a height of $20 \mathrm{~cm}$ followed by levelling. The microbeads and sand had similar bulk densities of $1.52 \mathrm{~g} / \mathrm{cm}^{3}$ and $1.50 \mathrm{~g} / \mathrm{cm}^{3}$, respectively.

\section{MECHANICAL BEHAVIOR}

The frictional properties of the microbeads and sand were determined using a model RST-XS ring-shear tester (Shulze 1994) according to the methodology described by Ellis et al. (2004), Panien et al. (2006a) and Gomes (2013), with constant linear shear velocity equal to $0.75 \mathrm{~mm} / \mathrm{min}$. To obtain more information about the microbeads' frictional behavior, we obtained the angle of internal friction and cohesion by filling the ring-shear test cell both sifting and pouring the granular material from a height of $20 \mathrm{~cm}$ (Table II). Although the result of this practice for sands is known in the literature (e.g., Lohrmann et al. 2003), we used it again for our sand to compare with the microbeads. To obtain the angle of basal friction, we only sifted the granular materials. The basal friction for the

TABLE I

Physical characteristics and mineralogical and chemical compositions of the sand and microbeads used in the physical models.

\begin{tabular}{|c|c|c|}
\hline Analog Material & Glass Microbeads & Quartz Sand \\
\hline \multicolumn{3}{|l|}{ SEM image } \\
\hline Granulometry & $0.180-0.300 \mathrm{~mm}$ & $0.210-0.350 \mathrm{~mm}$ \\
\hline $\begin{array}{c}\text { Bulk density } \\
\text { (sifted material) }\end{array}$ & $1.52 \mathrm{~g} / \mathrm{cm}^{3}$ & $1.50 \mathrm{~g} / \mathrm{cm}^{3}$ \\
\hline $\begin{array}{l}\text { Mineralogical composition/ } \\
\text { chemical composition (EDX) }\end{array}$ & $\begin{array}{c}78.2 \% \mathrm{SiO} 2 \\
12.84 \% \mathrm{Na}_{2} \mathrm{O} \\
2.30 \% \mathrm{MgO} \\
\pm \text { others }\end{array}$ & $\begin{array}{c}90 \% \text { quartz } \\
7 \% \text { feldspar } \\
3 \% \text { accessories }\end{array}$ \\
\hline Texture & Smooth & $\begin{array}{l}\text { Irregular surfaces } \\
\text { conchoidal fractures }\end{array}$ \\
\hline Roundness (Powers 1953) & Well-rounded to subrounded grains & Angular \\
\hline Aspect Ratio & 1.31 & 1.58 \\
\hline
\end{tabular}


microbeads was determined by overlying a card sheet and that for the sand by overlying both a card and plastic sheet (Fig. 1 and Table III). In the Figs. $2 \mathrm{~b}$ and $\mathrm{d}$, the slope of the straight lines that defines Coulomb envelopes, obtained by linear regression analysis, provides the angle of internal and basal frictions, respectively. The greatest statistical error of both angles of frictions that represent the mean of three ring-shear test cycles was $1-\mathrm{R}^{2}=0.144$.

Microbeads and sand have similar mechanical behavior, as seen in the Fig. 2a, which exemplifies the behaviors of both sifted materials by the curves of the highest normal load, $2400 \mathrm{~Pa}$..With increasing shear stress, the curves reveal initially elastic deformation that transitions to plastic deformation with increasing shear stress until failure at the peak strength. The failure is followed by a stage of strain softening until the dynamic-stable strength is reached. However, the microbeads fail at a much lower shear stress and slightly lower shear strain than the sand. The diagram reveals that the critical shear stress of the microbeads (1728 Pa) is attained after $50 \mathrm{~s}(\gamma=0.027)$, whereas the sand reached its peak strength $(2117 \mathrm{~Pa})$ at $54 \mathrm{~s}(\gamma=0.029)$. In addition, the strain softening (the difference between the coefficient of peak friction and the dynamic-stable friction divided by the coefficient of the dynamic-stable friction) of the sifted microbeads is lower $(31.45 \%)$ than that of the sand $(50 \%)$. Both the poured microbeads and the poured sand revealed lower angles of internal friction than the sifted materials, although the difference in the sand is slightly higher than in the microbeads (Table II). The second peak of the internal friction is lower than the first peak for all of the tested materials, as expected. The cohesions at peak friction, which were determined by extrapolating each straight line to the shear stress axis, are low and correspond to $58 \mathrm{~Pa}$ and $49 \mathrm{~Pa}$ for the shifted microbeads and sand, respectively. For the poured materials' the values of cohesions were higher as shown in Table II.

The peak friction curves in the plot of shear stress as a function of normal stress (Fig. 2b) confirm that microbeads are weaker than sand. In addition to the lower shear stress required for deformation, which was mentioned above, the microbeads are characterized by a smaller angle of internal friction $\left(34.1^{\circ}\right)$ than the sand particles $\left(41.5^{\circ}\right.$, Table II). The values reveal that the microbeads and sand that were used in our experiments have high angles of internal friction compared to those in other studies (e.g., Lohrmann et al. 2003, Rossi and Storti 2003, Panien et al. 2006a).

The behaviors of the microbeads and sand when sheared over different substrates are presented

TABLE II

Angles $\left(\Phi_{\mathrm{i}}\right)$ and coefficients $\left(\mu_{\mathrm{i}}\right)$ of internal friction, linearly extrapolated peak cohesion and ratio of strain softening for glass microbeads and sand.

\begin{tabular}{|c|c|c|c|c|c|c|}
\hline & & First peak & Second Peak & Dynamic-stable & $\begin{array}{l}\text { Apparent cohesion } \\
\text { (Pa) at first peak }\end{array}$ & $\begin{array}{c}\text { Strain Softening } \\
(\%)\end{array}$ \\
\hline \multirow{2}{*}{$\begin{array}{l}\text { Microbeads sifted } \\
\text { from } 20 \mathrm{~cm}\end{array}$} & $\phi_{\mathrm{i}}$ & $34.10^{\circ}$ & $29.25^{\circ}$ & $27.25^{\circ}$ & \multirow{2}{*}{57.80} & \multirow{2}{*}{31.45} \\
\hline & $\mu_{i}$ & $0.677 \pm 0.007$ & $0.560 \pm 0.008$ & $0.515 \pm 0.005$ & & \\
\hline \multirow{2}{*}{$\begin{array}{l}\text { Microbeads poured } \\
\text { from } 20 \mathrm{~cm}\end{array}$} & $\phi_{\mathrm{i}}$ & $31.13^{\circ}$ & $27.79^{\circ}$ & $26.01^{\circ}$ & \multirow{2}{*}{93.93} & \multirow{2}{*}{23.77} \\
\hline & $\mu_{i}$ & $0.604 \pm 0.014$ & $0.527 \pm 0.003$ & $0.488 \pm 0.003$ & & \\
\hline \multirow{2}{*}{$\begin{array}{l}\text { Sand sifted from } \\
\qquad 20 \mathrm{~cm}\end{array}$} & $\phi_{\mathrm{i}}$ & $41.47^{\circ}$ & $32.57^{\circ}$ & $30.49^{\circ}$ & \multirow{2}{*}{48.66} & \multirow{2}{*}{50.00} \\
\hline & $\mu_{\mathrm{i}}$ & $0.884 \pm 0.16$ & $0.639 \pm 0.002$ & $0.589 \pm 0.002$ & & \\
\hline \multirow{2}{*}{$\begin{array}{l}\text { Sand poured from } \\
20 \mathrm{~cm}\end{array}$} & $\phi_{\mathrm{i}}$ & $37.97^{\circ}$ & $33.86^{\circ}$ & $31.58^{\circ}$ & \multirow{2}{*}{137.47} & \multirow{2}{*}{26.99} \\
\hline & $\mu_{\mathrm{i}}$ & $0.781 \pm 0.0106$ & $0.671 \pm 0.018$ & $0.615 \pm 0.028$ & & \\
\hline
\end{tabular}




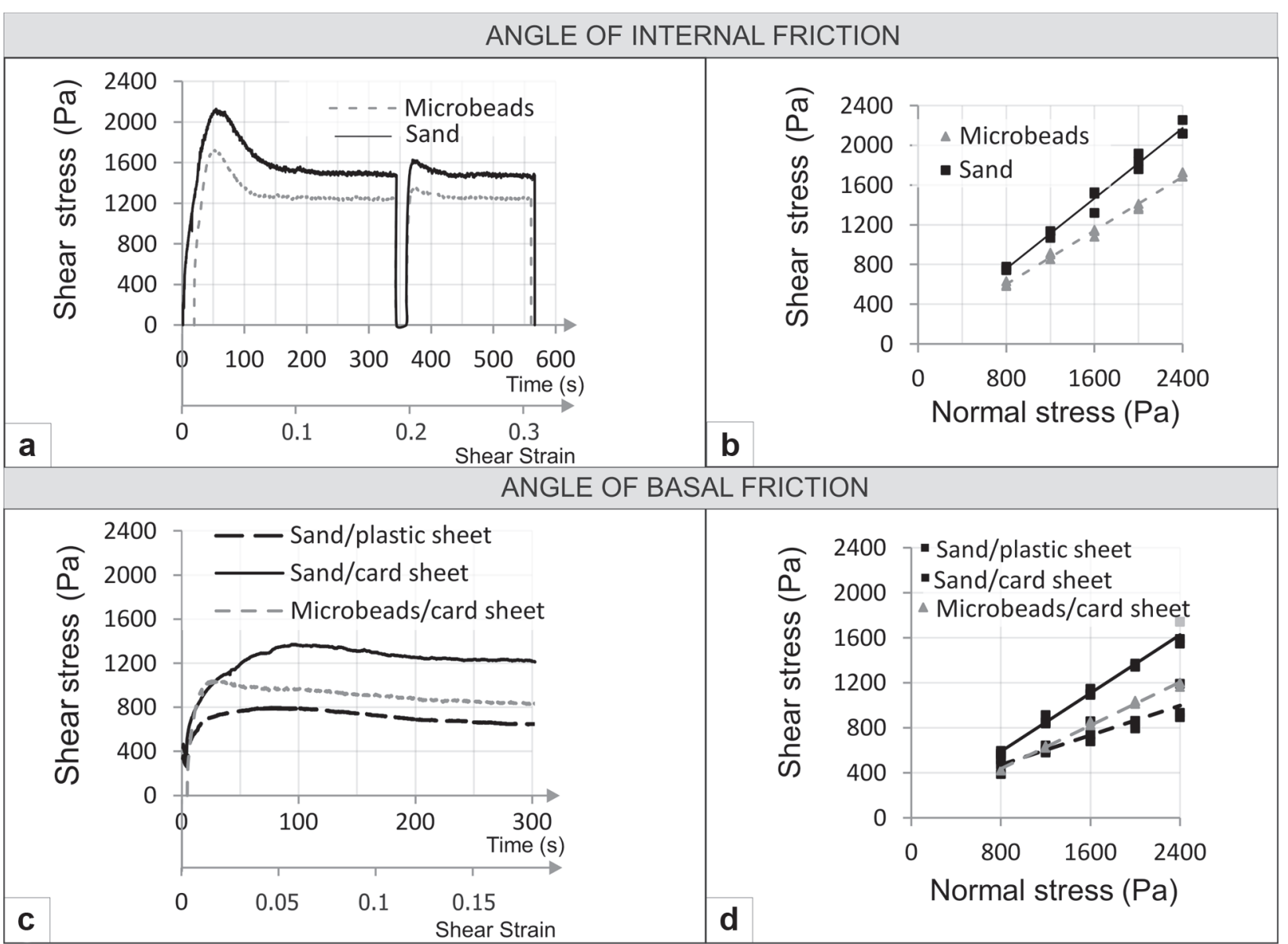

Figure 2 - Ring-shear test results. The diagrams a and $\mathbf{c}$ show shear stress as a function of time and of angular shear strain with strain-stress curves at a normal stress of $2400 \mathrm{~Pa}$ and $2000 \mathrm{~Pa}$, respectively. The time on the horizontal axis refers to the time interval that the ring-shear tester rotated until failure (the shear strain was not measured). In figure $\mathbf{c}$ the second peak is not shown because it was an unimportant basal friction parameter. The plots in figures $\mathbf{b}$ and $\mathbf{d}$ shows shear stress as a function of normal stress with the peak friction curves. In figure $\mathbf{b}$ the slightly lower slope of the microbeads curve indicates its lower angle of internal friction.

in the 2000 Pa normal load curves in Fig. 2c. The curves that represent the basal peak friction and the basal dynamic-stable strength show that the microbeads that overlie a card sheet require an intermediate level of shear stress to deform and a lower shear strain than the sand. Similarly to the internal friction, the second peak was lower than the first peak (Table III). In addition, the three peak friction curves in the plot of shear stress as a function of normal stress (Fig. 2d) illustrate that the microbeads that were over a card sheet have an intermediate angle of basal friction $\left(25.7^{\circ}\right)$, whereas those of the sand over a card sheet and over a plastic sheet are $32.9^{\circ}$ and $18.2^{\circ}$, respectively (Table III).

\section{ANALOG PHYSICAL MODELING}

\section{EXPERIMENTAL LIMITATIONS}

In our experiments, the rigid vertical mobile back wall acted as an indenter that influence the build up of our thrust wedge. Consequently, the wedge height and slope increased anomalously during the initial shortening, and the first fault nucleated closer to the mobile wall than expected. Thus, a rigorous analogy between our wedges and the Critical Coulomb Wedge theory was prejudiced. However, the progressive deformation of the wedges in the low and medium basal friction models suggests that the effect of internal and basal friction follows 
TABLE III

Angles $\left(\Phi_{\mathrm{b}}\right)$ and coefficients $\left(\mu_{\mathrm{b}}\right)$ of basal friction for glass microbeads and sand over different substrates.

\begin{tabular}{ccccc}
\hline Experiments numbers & & First Peak & Second peak & Stable-dynamic \\
\hline MB1 = S1 & $\phi_{\mathrm{b}}$ & $18.21^{\circ}$ & $15.62^{\circ}$ & $15.78^{\circ}$ \\
\cline { 2 - 5 } (sand over a plastic sheet) & $\mu_{\mathrm{b}}$ & $0.329 \pm 0.144$ & $0.279 \pm 0.0163$ & $0.282 \pm 0.0184$ \\
\hline MB2 $=\mathrm{S} 2$ & $\phi_{\mathrm{b}}$ & $25.68^{\circ}$ & $18.57^{\circ}$ & $18^{\circ}$ \\
\cline { 2 - 5 } (microbeads over a card sheet) & $\mu_{\mathrm{b}}$ & $0.482 \pm 0.0046$ & $0.336 \pm 0.0374$ & $0.325 \pm 0.0438$ \\
\hline MB3 $=\mathrm{S} 3$ & $\phi_{\mathrm{b}}$ & $32.94^{\circ}$ & $32^{\circ}$ & $31.92^{\circ}$ \\
\cline { 2 - 5 }$($ sand over a card sheet) & $\mu_{\mathrm{b}}$ & $0.648 \pm 0.015$ & $0.623 \pm 0.013$ & $0.592 \pm 0.006$ \\
\hline
\end{tabular}

the rules of the Critical Coulomb Wedge theory. In addition, the rigid vertical mobile back wall that was used for both model series did not interfere with the experimental comparisons.

Our models addressed the evolution of thrust wedges but neglected many factors, such as syntectonic erosion and sedimentation, fluid phases, and the mechanical stratigraphy of natural sedimentary successions. Despite these limitations and precisely because of the simplified conditions, the first-order features of our thrust wedge experiments adequately illustrate the behavior of microbeads.

Another limitation of our models is that the measurements through the glass side walls are slightly influenced by lateral friction. For comparison, we present photographs of central cross sections at the end of shortening for all the models. The internal sections reveal subtle differences in the Coulomb wedge geometry in all of the models. In these sections, the wedges are slightly lower but longer than those along the side wall. In addition, the number of failures varies slightly but the fault geometry does not vary significantly.

\section{EXPERIMENTAL METHOD}

The experimental apparatus consists of a glasssided acrylic box, whose model dimensions (length and wide) and thickness are shown in Fig. 1b. An electric motor produces shortening by pushing the mobile frontal wall at a constant rate of $2.3 \mathrm{~cm} / \mathrm{h}$. All the experiments have been repeated twice and since each set presents similar wedge evolution, wedge geometry and number of major thrusts that always initiate at the same moment, the results have been considered to be reproducible.

We measured the following parameters during the progressive deformation: fault spacing, wedge thickness near the mobile wall, slope angle and length. The wedge length was measured when a fault trace emerged in map view, and the fault spacing was measured when the trace of a new fault appeared in the lateral profile (Fig. 1c).

The sand and microbeads were artificially dyed and deposited in the experimental boxes by sifting followed by slight compaction. All of the experiments were shortened by $16 \mathrm{~cm}(38 \%)$, and the progressive deformation was documented by digital photographs at every $1 \mathrm{~cm}$ of shortening.

The validity of the tectonic analog models is addressed by the theory of scale models, which is controlled by a set of geometric, kinematic and dynamic similarity criteria, as discussed by several authors (e.g., Hubbert 1937, Ramberg 1981, Koyi 1997, Graveleau et al. 2012 for more details). Our model-to-prototype ratio for length was $1 \times 10^{-5}$ so that our initial $3 \mathrm{~cm}$-thick model simulates the brittle upper $3 \mathrm{~km}$ of shallow crust.

\section{RESULTS}

We do not provide a detailed description of each experiment but instead describe the differences and similarities between the models. We only present the progressive deformation of the medium basal 
friction models of each experimental series: the microbeads model "MB2" and the sand model "S2" (Fig. 3). The other experiments are only presented at the end of deformation (Fig. 4).

In MB2 and S2, the shortening produced slight thickening in front of the mobile wall, followed by thrusting. The progressive deformation revealed the counterclockwise rotation of the lower fault segment that resulted in a convex-up geometry for the fault trace in the sand models. In MB2, only the oldest fault (designed with the number 1 in Fig. 3; hereafter, these numbers are referred to as F1, F2, etc.) showed a comparable convex-up geometry. However, the geometry of this fault in the central section is similar to that of the younger faults (Fig. 4a). In contrast to model MB2, the counterclockwise rotation of the lower fault segment in the sand model produced strong vertical ejection of the granular material near the mobile wall. In this model, progressive deformation caused the older faults to climb over the youngest as already described in previous models (e.g., Mulugeta 1988, Liu et al. 1992, Koyi and Teixell 1999).

The final deformation of models MB2 and S2 (Fig. 3) revealed differences in the fault geometry, in the formation of short faults with small or negligible slip and in the strain transmission along the experimental box base. In addition, a minor difference was detected in the fault-propagation folds, which are slightly more rounded in the microbeads than those in the sand model (compare the upper parts of the photographs and linedrawings in Fig. 3). In model MB2, long thrusts entirely cut the microbeads layers and present high slip but are irregularly curved, which differs from the sand models. The negligible slip of the short thrusts produced minor shear folds in model MB2. Because the successive microbeads layers do not present the same wavelengths and amplitudes, the structures resemble disharmonic folds.

The dip angles at the moment that the thrusts nucleated (prior to $2 \mathrm{~cm}$ of shortening in both models) and the width of the fault zones are apparently similar between the microbeads and sand. Differences may occur, but these variations would have to be measured with a more sophisticated technique, such as X-ray computed tomography (CT).

The deformation style of model MB1 is similar to that of model MB2 (Fig. 4a), and the main differences between models MB1 and S1 are similar to those between models MB2 and S2 (Figs. 4a and $b$ ). The surface line-drawings of the fault traces of models MB1 and S1 support the higher number of thrust faults in the microbeads experiment compared to the sand models (Fig. 5). However, model MB1 produced a smaller number of short faults with negligible slip than MB2; consequently, disharmonic folds are not evident. Similarly to the sand experiments, only the microbeads models with low and intermediate basal frictions formed backthrusts; among these, MB1, the model with the lowest basal friction, produced the highest number of backthrusts.

In models MB3 and S3, the high angle of basal friction prevented the analog materials from advancing during progressive deformation. Thus, the microbeads and sand in these models deformed through similar processes, which were characterized by strong convex-up listric fault geometry and grain ascension along the rigid mobile wall. Fault partitioning was a minor process in model MB3; however, some faults branched at their terminations.

A comparison between models S2 and S2-b (Fig. 4b) showed a difference in the amount of slip on both F5 faults that resulted from the motion of microbeads along this plane. In S2-b a larger amount of slip occurred because of stronger lubrication along the fault plane. In addition, the high mobility of the rounded to sub-rounded microsphere grains resulted in the thickening of the basal layer and its rise along the mobile wall in both experiments. 


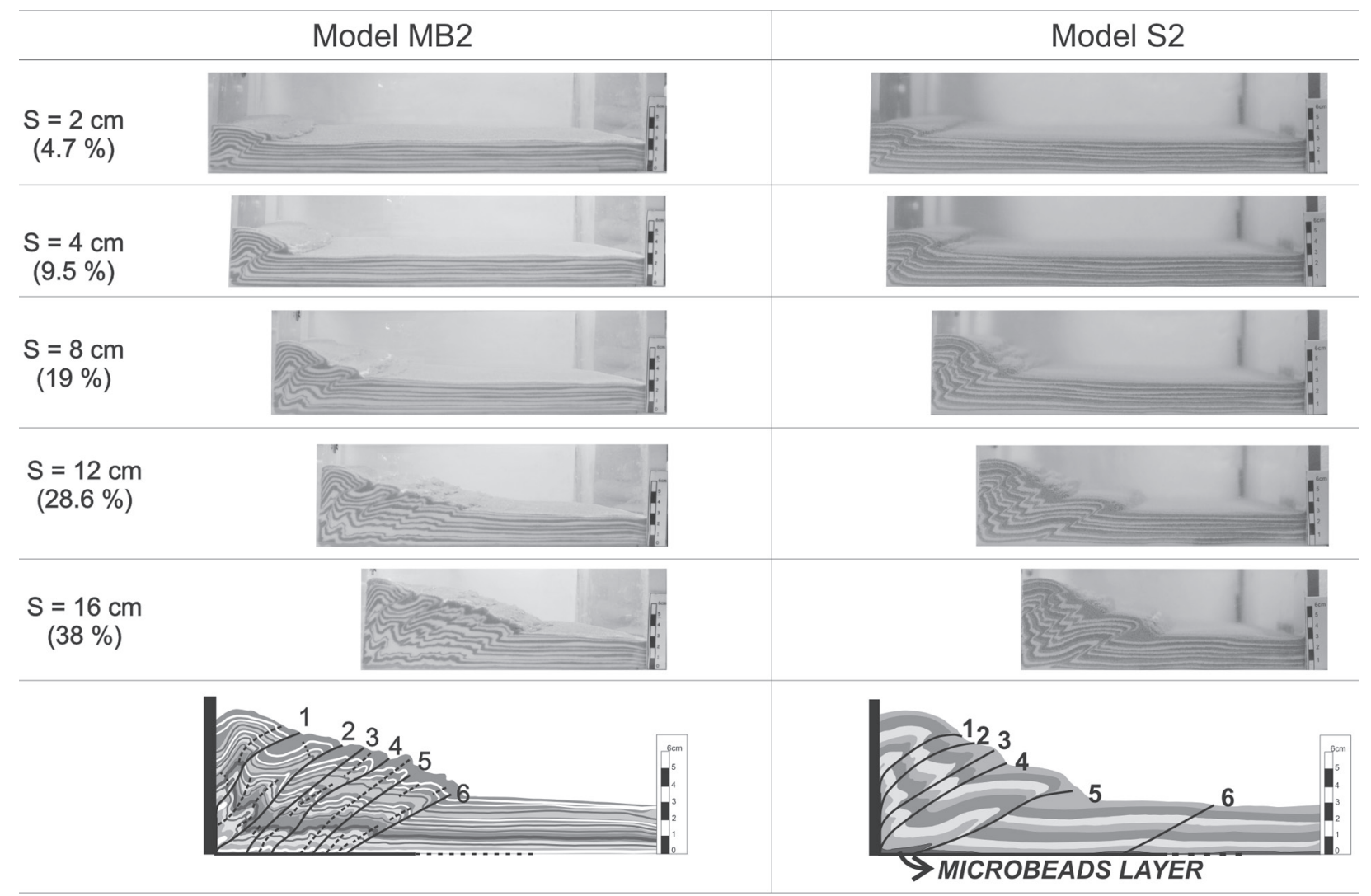

Figure 3 - Photographs of the progressive deformation of the medium basal friction models MB2 and S2 $\left(\phi b=25.68^{\circ}\right)$. Linedrawings of the final shortening with their interpretation are amplified to better show details. In model MB2, faults with minor slips are dashed and only the long faults are numbered. The numbers indicate the sequence in which they formed; $\mathrm{S}=$ shortening. (Export resolution of digital photographs: $300 \mathrm{dpi}$ ).

The analysis of the measured parameters (wedge thickness near the mobile wall, slope angle, length and fault spacing) for the seven experiments (Fig. 6) confirmed the results of the physical models of critical sand wedges that were described in the literature (e.g., Schreurs et al. 2006, Teixell and Koyi 2003, Liu et al. 1992, Agarwal and Agrawal 2002). Similarly to the sand, the slope angles in the microbeads models increased during progressive deformation and when a new thrust nucleated, the slope angle decreased and then resumed growing (Fig. 6b). In contrast, the wedge length increased each time a new fault formed and decreased in subsequent intervals (Fig. 6c). The slope angles in our models were always extremely high because of the proximity of the rigid vertical mobile back wall, as mentioned above.
Despite the differences in the thrust geometry and number of faults, the low and intermediate basal friction models formed similar wedges. The high basal friction models MB3 and S3 formed both similar wedges and similar fault geometries and numbers, confirming the strong influence of a high basal friction on the deformation of granular material.

The wedge thickness near the mobile wall and the wedge slope angle increased from the low to high basal detachment models, whereas the wedge lengths decreased (Figs. 6a, b and c). The fault spacing was also related to the basal friction, with higher basal friction producing lower fault spacing (Fig. 6d). The wedge thickness near the mobile wall and the fault spacing are always lower in the microbeads models MB1 and MB2 than in the sand 


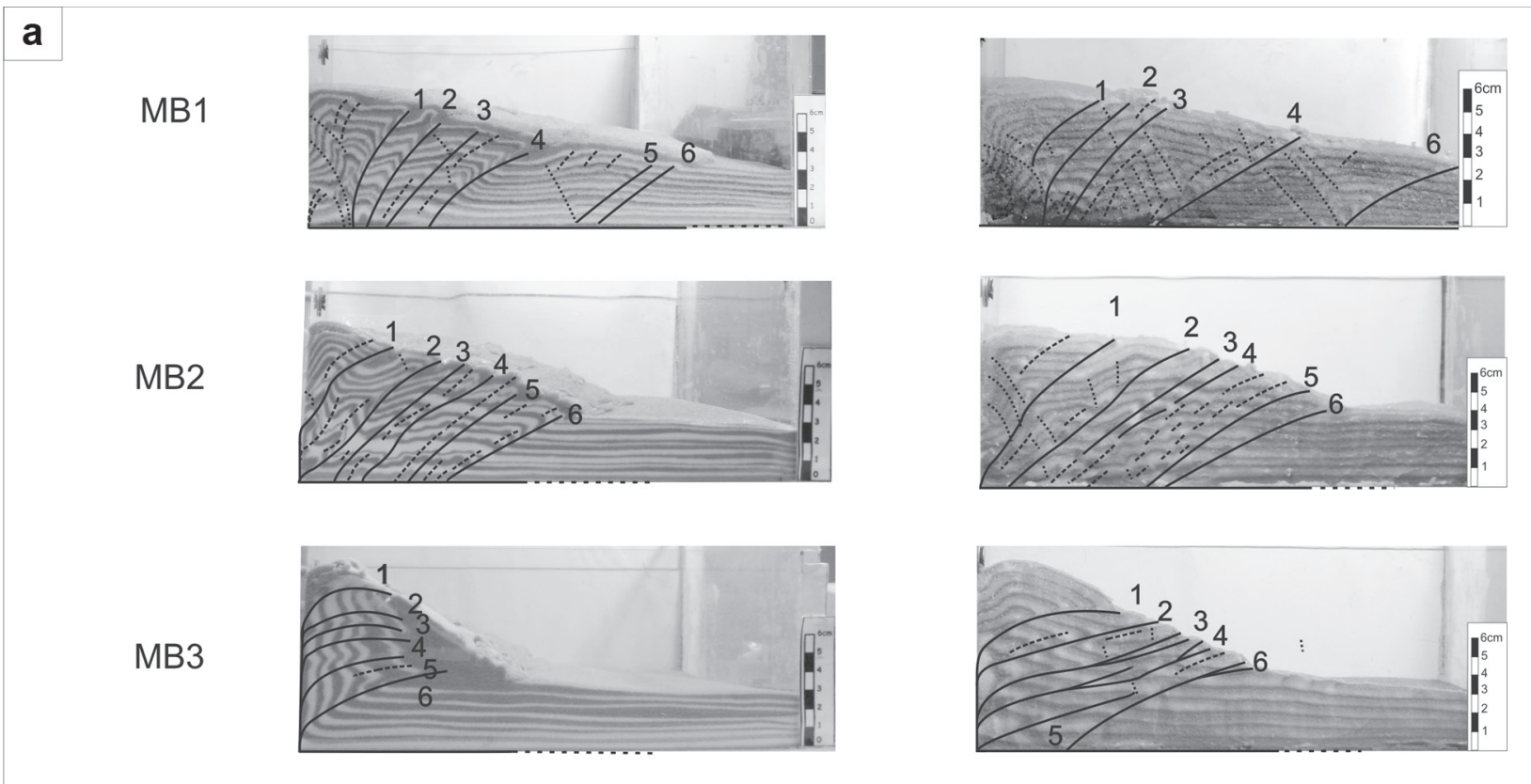

b

S1
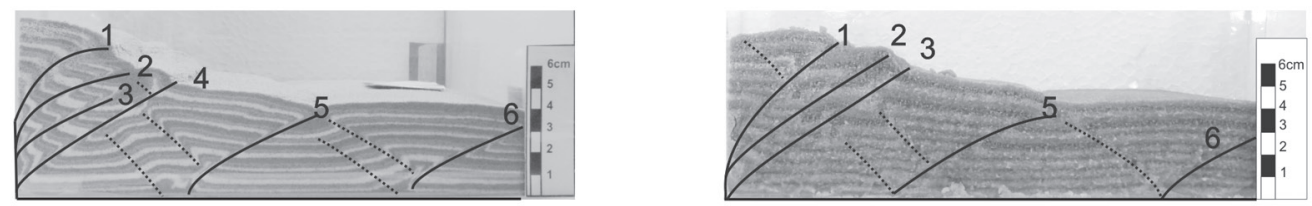

S2
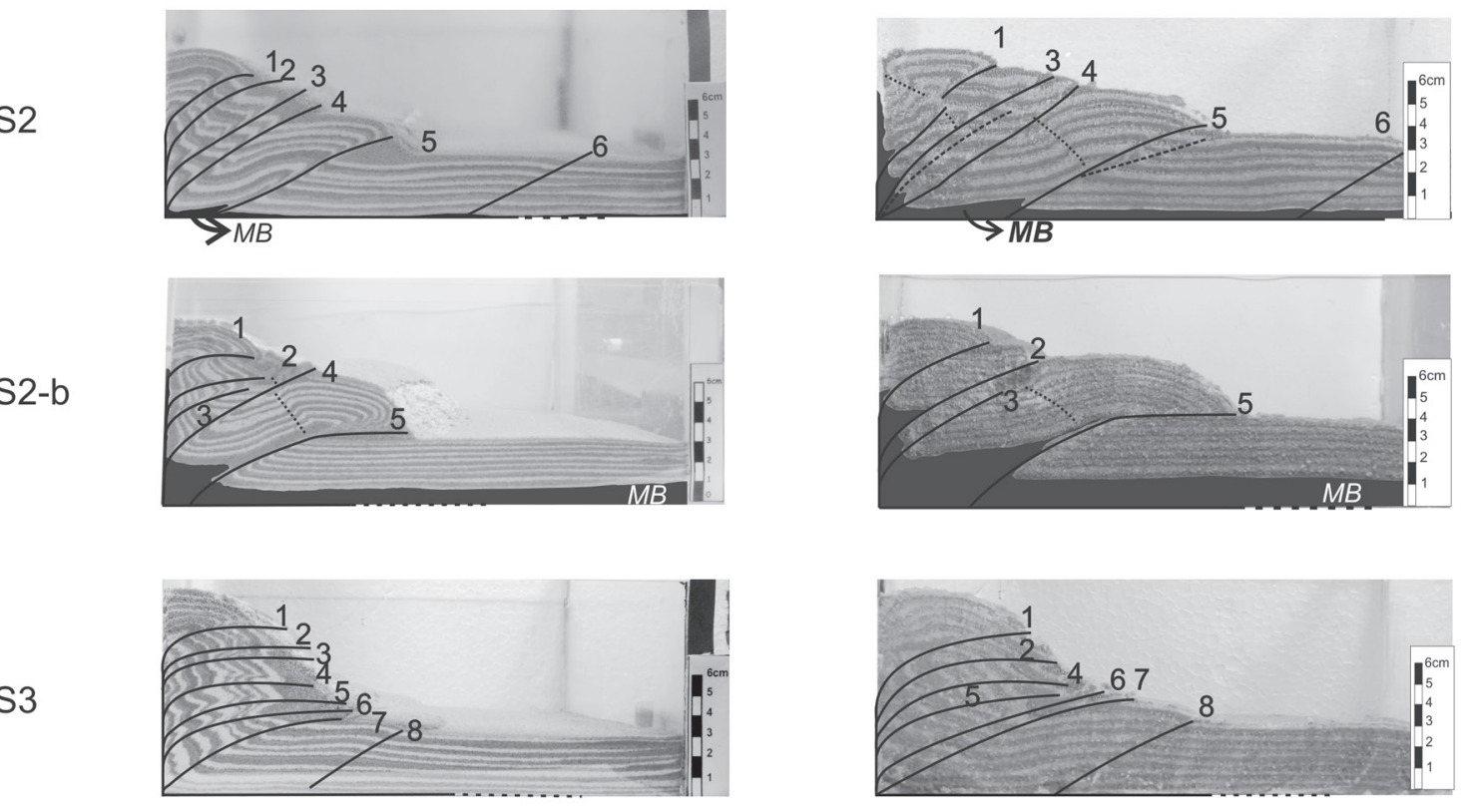

Figure 4 - Left column: Sidewall photographs of the three microbeads models (a) and the four sand models (b) at the end of shortening. Right column: photographs of the central cross sections of the same models. The numbers indicate faults in the sequence in which they formed. Faults with minor slips are dashed and not numbered, and some faults are visible only in the sidewall. The microbeads basal layers in the S2 and S2-b models, are shown in dark gray to be better distinguished. (Export resolution of digital photographs: $300 \mathrm{dpi}$ ). 


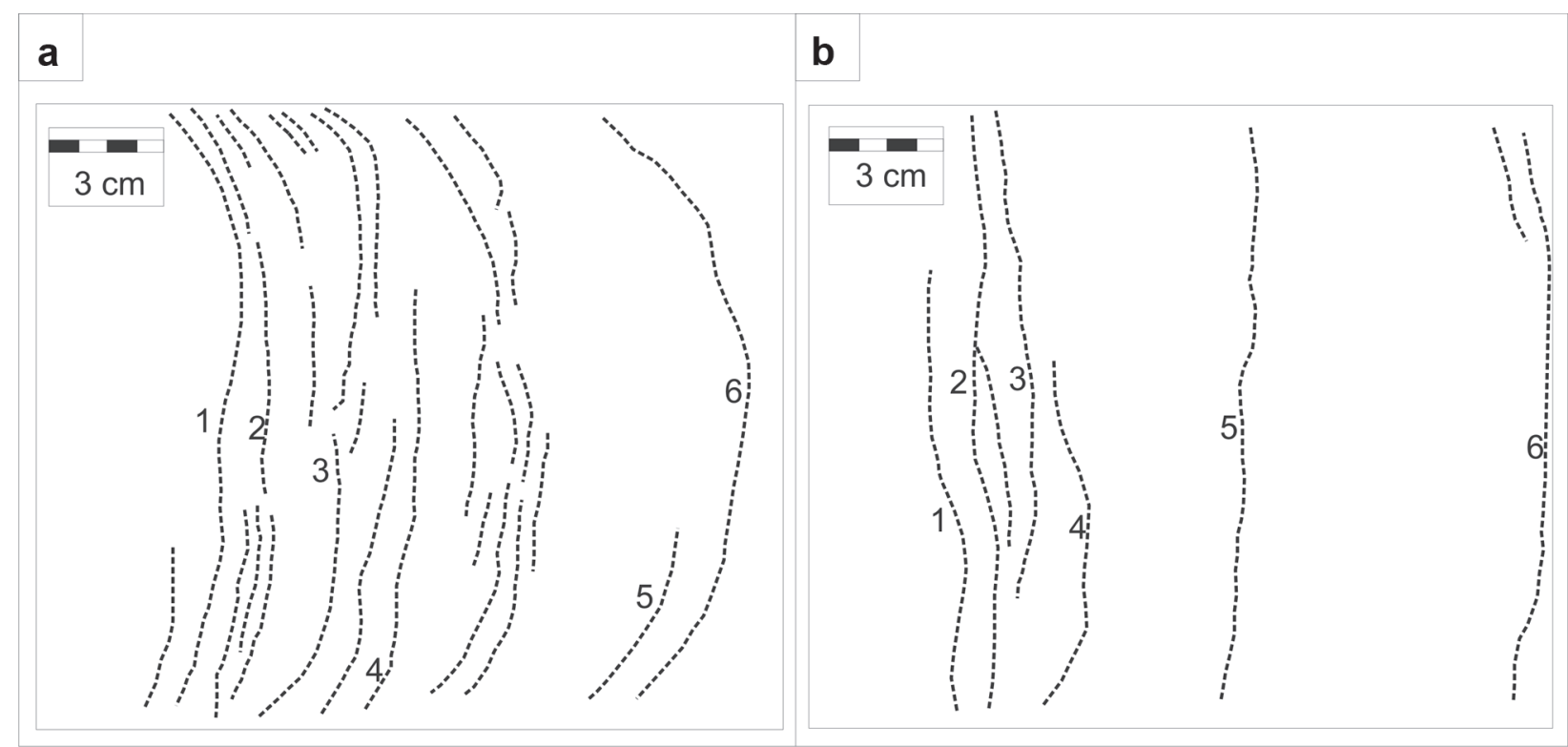

Figure 5 - Line-drawings of the surface photographs of models (a) MB1 and (b) S1 at the end of deformation. Note the large number of faults in model MB1. Only the faults that were also recognized in the cross sections are numbered.

models S1 and S2. In contrast, the slope angles and lengths of the wedges are heterogeneous, which is similar to all of the parameters in models MB3 and S3.

\section{DISCUSSION}

The measured parameters (wedge thickness near the mobile wall, slope angle, length and fault spacing) were remarkably similar between the microbeads and sand wedges. However, the physical models showed differences in the deformation of the microbeads and sand due to their distinct rheological behaviors. The low and medium basal friction microbeads experiments, MB1 and MB2, produced a high number of short faults with low slip in addition to the thrusts that cut the microbeads packs from the base to the top. According to Rutter (1986), plasticity in brittle materials is predominantly caused by slips on minor faults; depending on the physical conditions of the deformation, intracrystalline plasticity and flow by diffusive mass transfer may occur. According to the large number of short faults with small slip, our ring-shear tests and those by Panien et al. (2006a) (their Fig. 7) revealed that microbeads fail earlier than sand. Thus, microbeads must produce a higher number of faults according to our models' deformation time $(\approx 7 \mathrm{~h})$. Furthermore, Panien et al. (2006a) suggested that microbeads accommodate shear by stress chains or so-called 'localized particle chains'. These chains are considered to be unstable because only a few grains are in contact with each other, which results in high individual contact stresses. Thus, angular and subangular sand grains have longer time intervals until failure than more rounded grains do because of the greater number of grains that are in contact. This reasoning suggests that other glass microbeads, such as perfectly spheroidal or well-rounded to sub-rounded grains, similar to ours, may produce features similar to those described here.

The strongly convex-up thrust faults and the resultant vertical grain ejection at the rigid mobile wall were notable features in the sand models. Accordingly to Teixell and Koyi (2003) and Gomes (2013), thrusts in sand models become convex upwards because the lower thrust segment steepens due to volume reduction (by layer-parallel 


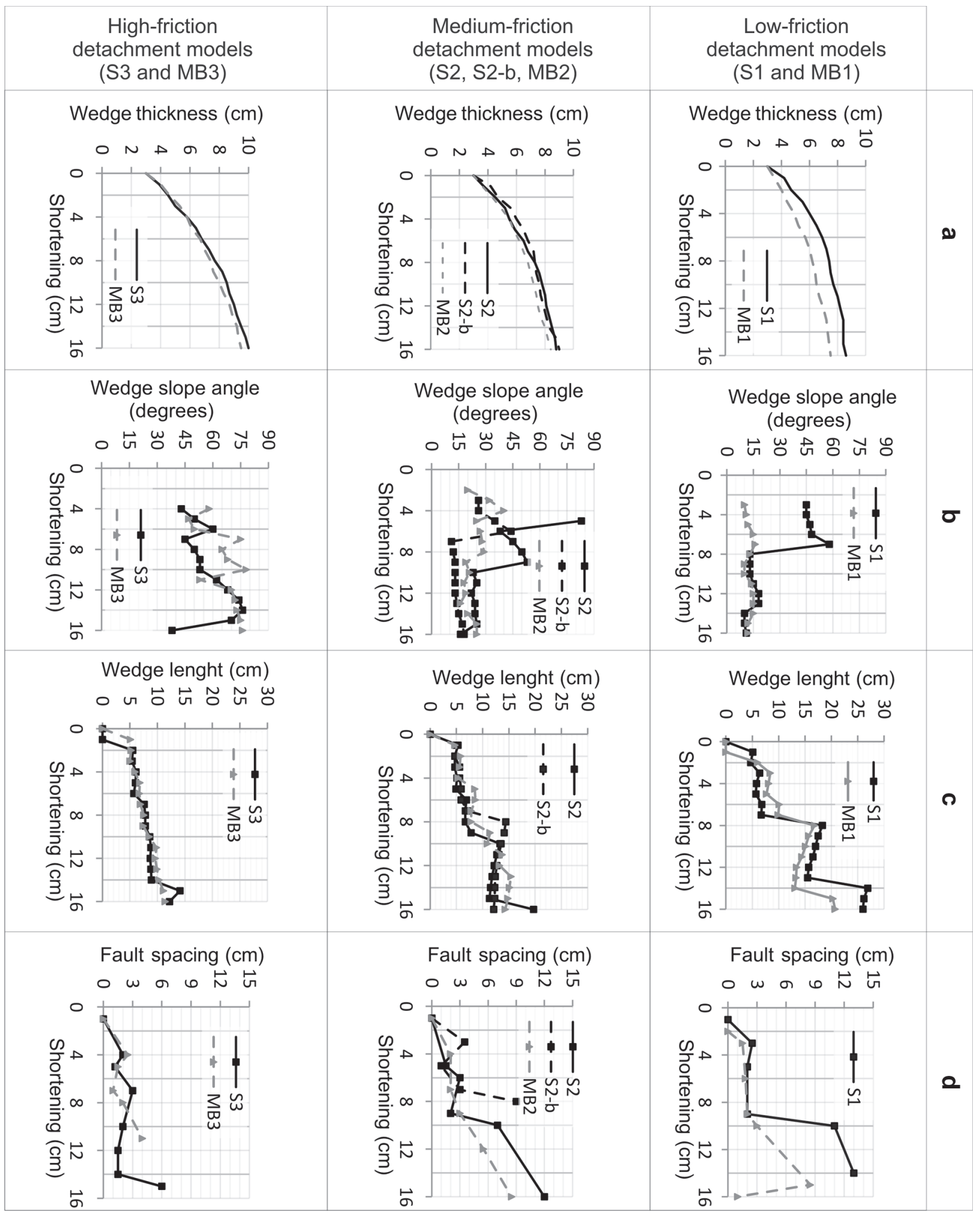

Figure 6 - a) Plots of the wedge thickness near the mobile wall with shortening. b) Plots of the wedge slope angle with shortening. c) Plots of the wedge length with shortening. d) Plots of the fault spacing with shortening. 
shortening) in the foreland during progressive deformation. This process is strongest in the deep layers and consequently produces a buttress effect due to the compaction of grains. We suggest that the long thrusts in the microbeads models MB1 and MB2 do not present the same strong curvature as sand because of the low compaction of microbeads, which accommodate shortening mainly by slip between grains. Model MB3 is different due to its high basal friction.

The slip between microbeads grains facilitates flow due to their roundness, a property that is commonly used in the literature to simulate ductile detachment zones. In our models that exclusively feature microbeads, this property was not conspicuous but was obvious in the $\mathrm{S} 2$ and S2-b models, along the F5 faults. We suggest this microbeads grain flow occurred in these models because particles were trapped below the sand pack and thus, escaped along weak zones due to their roundness. The opposite did not occur with the sand that composed the basal layer in the microbeads models MB1 and MB3. Sand grains are angular to sub-angular, and flow in the foreland of sand models occurs, subordinately, during layer-parallel shortening, which would be only detectable by the Particle Image Velocimetry (PIV) technique (e.g., Adam et al. 2005, Nilfouroushan et al. 2012). Along the rigid mobile wall in the $\mathrm{S} 1$ and $\mathrm{S} 3$ models, the vertical flow of sand occurred because of an extreme contrast in the rheology between the mobile wall and the sand.

In the high basal friction experiments $\mathrm{S} 3$ and MB3, the wedge materials did not significantly influence the deformation, and their deformation styles are similar. Shortening produced antiformal stacks in both models, in contrast to the imbricate stack that formed in the lower basal friction models, and slips on the minor faults were insignificant. This observation suggests that slips on minor faults are limited and that ductility mainly involves grain flow.
COMPARISON WITH EXPERIMENTS FROM THE LITERATURE

The microbeads that were employed by Panien et al. (2006a) had smaller angles of internal friction than those in our experiments $\left(22.3^{\circ}\right.$ and $34.1^{\circ}$, respectively). Because the handling techniques were the same, the differences may be explained by the grain texture, roundness and form. The situation with sand was different. Despite being less angular, the sand that was used in this study had a higher angle of internal friction $\left(\varphi_{i}=41.5^{\circ}\right)$ than the sand that was used by Panien et al. (2006a) $\left(\varphi_{\mathrm{i}}=35.5^{\circ}\right)$. Curiously, the glass fragments that were used by Panien et al. (2006a) had a similar angle of internal friction to ours, but the grains were very angular and had a greater aspect ratio of 2.19. Because of their physical characteristics (high angularity associated with high porosity), it may be inferred that the glass fragments became as tightly packed as the sand that was used in this study when subjected to high shear stresses, which may have produced the similar angles of internal friction.

Thus, we confirm the conclusions that were obtained by Lohrmann et al. (2003) and Maillot (2013), namely, the angle of internal friction partly depends on the material's porosity, which leads to greater or less packing and, in turn, depends on the shape and size distribution of the grains.

Other researchers have analyzed the effect of weak granular materials in shortening experiments. A common feature that has been described in those studies was fault partitioning because of distributed deformation, which is characterized by several large faults and numerous minor faults. Rossi and Storti (2003) proposed the use of hollow aluminium and hollow siliceous microspheres, which are characterized by high sphericities and low angles of internal friction of $24.7^{\circ}$ and $23.9^{\circ}$, respectively. These microspheres were interlayered with quartz sand to simulate strongly anisotropic multilayers. 
The experiments of Rossi and Storti (2003) produced a highly disharmonic deformation pattern that was similar to the distributed deformation style of our models MB2 and MB1.

Eisenstadt and Sims (2005) compared compression, extension and inversion experiments that were performed with dry sand and wet clay and concluded that clay produced similar largescale deformation patterns as sand despite several key differences. These differences were related to the high ductility of wet clay because of its higher cohesion and smaller grain size. The distributed deformation in wet clay produced strong fault partitioning, folding as a result of grain flow and reactivation of extensional faults during inversion.

Gomes (2013) and Gomes et al. (2015) described fault partitioning that resulted from distributed deformation in analog experiments that were performed with a sand-mica mixture (14:1 by weight). This mixture had a similar angle of internal friction to sand but failed at a lower peak shear stress because its strength was lower. The more plastic character of the sand-mica mixture compared with the sand was confirmed by additional ring-shear tests, which showed that the stress-strain curve of the sand-mica mixture was softer than that of sand. The highly angular mica crystal grains interlocked more with increased shortening compared to the sand. Therefore, the sand-mica mixture produced more compaction than the sand and, thus, more rounded fault-propagation folds in addition to fault-partitioning and grain flow. This mixture is supposed to be used to simulate supracrustal rocks that overlie a more competent basement that is represented by sand in thick skinned tectonics.

\section{THE POTENTIAL APPLICATION OF MICROBEADS} WEDGES

Regional shortening during plate convergence and collision is usually simulated in physical models by the elastic-plastic frictional behavior of quartz sand, which accounts for faulting and fault-related folding (particularly fault-propagation folds). Slightly more plastic glass microbeads provide faults and fault-propagation folds but also produce small-scale deformation features that contribute to a more plastic strain regime.

Contrasting with the assumption that microbeads may be used to simulate incompetent rocks, such as under compacted shales, due to their weakness (Panien et al. 2006a), we suggest that microbeads wedges may be used to simulate relatively competent rocks. Carbonate rocks may be an example of such rocks. Folded carbonates are common in several thrust belts, such as the Zagros fold thrust belt in Iran (e.g., Sepehr et al. 2006) and the fold-thrust belt of the Alps (Decarlis et al. 2014). Microbeads may be used to simulate tectonic situations in which small-wavelength (parasitic) folds are associated with regional-scale faultrelated folds, such as those in the Late Cretaceous marly limestones in the external Alps (VentimigliaMenton area) (Decarlis et al. 2014, Fig. 7). In this region, the Meso-Cenozoic sedimentary succession experienced positive inversion during the OligoMiocene Alpine deformation, creating a complex pattern of thrusts and related folds in various scales and geometries.

\section{CONCLUSIONS}

Our investigation showed that microbeads wedges and sand wedges produce slightly different deformation features when subjected to the same shortening conditions. Although both materials have elastic-frictional plastic behaviors, the deformation mechanisms in the microbeads pack contributed to more distributed deformation than that in the sand.

In both materials, the deformation mechanisms included failure and grain flow. However, the mechanisms acted differently in sand and microbeads packs due to the beads' roundness and texture. During shortening in microbeads packs, 


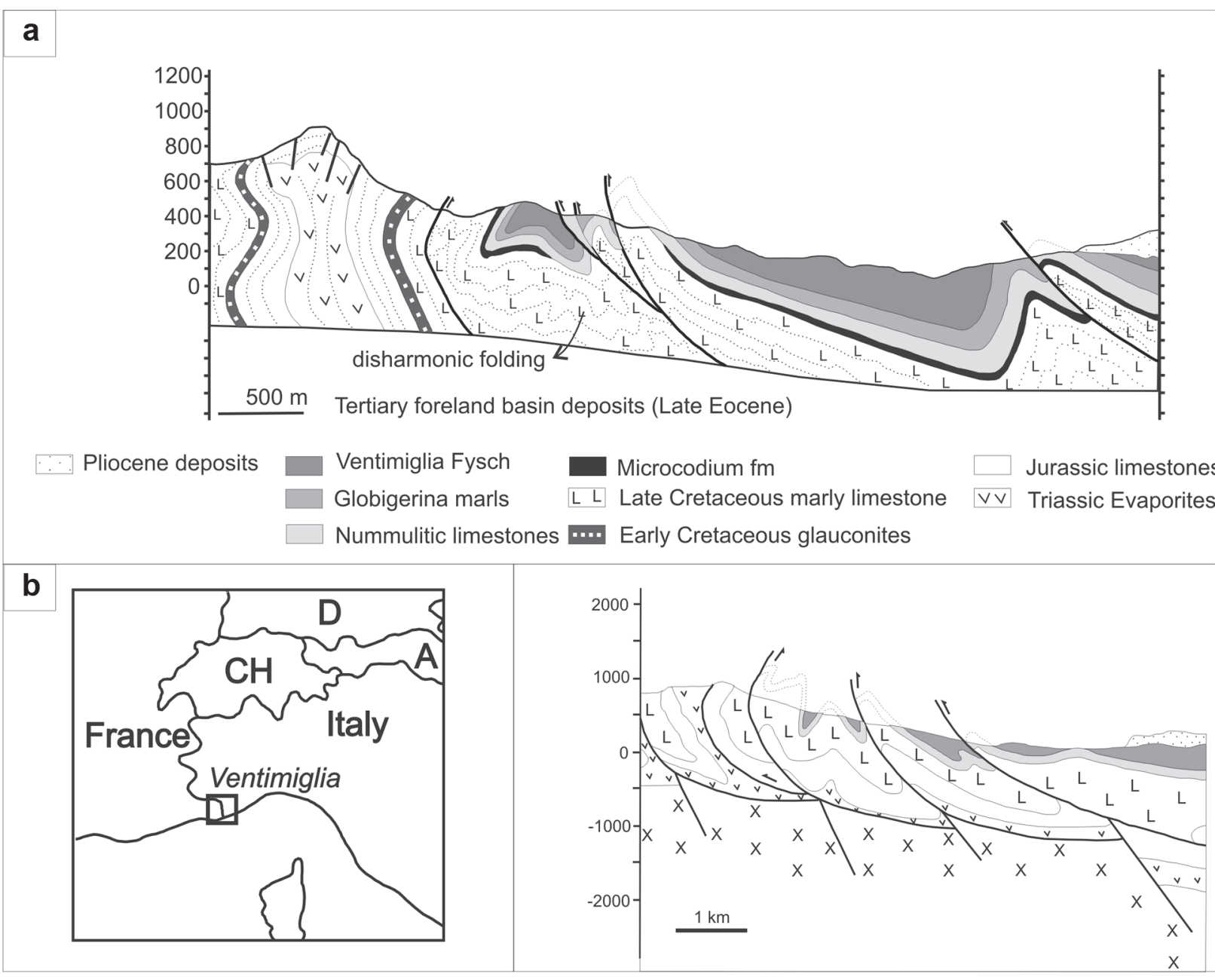

Figure 7 - (a) An east-west cross-section of the Ventimiglia-Menton area (external Alps) that was studied by Decarlis et al. (2014) (see the inset below for the location), which shows secondary disharmonic folds in Late Cretaceous marly limestones. (b) Part of a near-by balanced cross-section that illustrates the structural context (modified from Decarlis et al. 2014).

failure included localized and distributed fracturing (the formation of short faults with low slip). In the deep layers, slip on the smooth and rounded microbeads impeded the compaction of grains and the resultant buttress effect, which was detectable in the sand packs. Thus, the fault geometries in the sand and microbeads packs were different.

The shortening of the microbeads pack confirmed the role of basal friction in the physical models. When the microbeads pack was shortened over different basal friction detachments, the wedge geometries were similar to those of the sand. The low basal friction produced a low wedge thickness and slope and a high wedge length, fault spacing and backthrust frequency. In addition, we observed that the grain shape influenced the deformation style only for a low to intermediate basal friction $\left(\leq 25.7^{\circ}\right)$. When the basal friction was high, the deformation style of more angular (sand) grains was dominant.

A comparison of the physical properties of the analog material grains in this study with data from the literature showed that physical properties are as important as frictional properties because the angular sand that was used in this study had approximately the same peak friction as the very angular glass fragments that were used by Panien et al. (2006a). 
We conclude that microbeads, when used as a pack in physical models, may be employed to simulate the shortening of relatively competent rock sequences in brittle crust. The advantages of using microbeads over other elastic/frictional-plastic granular materials (e.g., hollow aluminium and hollow siliceous microspheres, wet clay, and sandmica mixtures) are their low cost, homogeneous composition and ease of use, including the dying process.

\section{ACKNOWLEDGMENTS}

The authors acknowledge PETROBRAS, which financed the acquisition of the ring-shear tester, and the MICROLAB-DEGEO-UFOP staff for their help in performing the analysis and with the scanning electron microscope. We also acknowledge Fundação de Amparo à Pesquisa do Estado de Minas Gerais (FAPEMIG) (CRAAPQ-01672-11 and CRA-PPM-00531-13) for their financial support and we would like to thank the anonymous reviewers. Finally, we wish to express our thanks to Universidade Federal de Ouro Preto, which provided financial support for language editing.

\section{REFERENCES}

ADAM J, URAI JL, WIENECKE B, ONCKEN O, PFEIFFER K, KUKOWSKI N, LOHRMANN J, HOTH S, VAN DER ZEE W AND SCHMATZ J. 2005. Shear localization and strain distribution during tectonic faulting - new insights from granular-flow experiments and high-resolution optical image correlation techniques. J Struc Geol 27: 283301.

AGARWAL KK AND AGRAWAL GK. 2002. Analogue Sandbox Models of Thrust Wedges with Variable Basal Frictions. Gondwana Res 5(3): 641-647.

BONNET C, MALAVIEILLE J AND MOSAR J. 2007. Interactions between tectonics, erosion, and sedimentation during the recent evolution of the Alpine orogen: analogue modeling insights. Tectonics 26, TC6016.

DECARLIS A, MAIANO M, DALLAGIOVANNA G, LUALDI A, MASINI E, SENO S AND TOSCANI G. 2014. Salt tectonics in the SW Alps (Italy-France): From rifting to the inversion of the European continental margin in a context of oblique convergence. Tectonophysics 636 : 293-314.

EISENSTADT G AND SIMS D. 2005. Evaluating sand and clay models: do rheological differences matter? J Struct Geol 27: 1399-1412.

ELLIS S, SCHREURS G AND PANIEN P. 2004. Comparisons between analogue and numerical models of thrust wedge development. J Struct Geol 26(9): 1659-1675.

GOMES CJS. 2013. Investigating new materials in the context of analog-physical models. J Struct Geol 46: 158-166.

GOMES CJS, D'ANGELO T AND ALMEIDA G. 2015. Testing the influence of a sand mica mixture on basin fill in extension and inversion experiments. An Acad Bras Cienc 87: $51-62$.

GRAVELEAU F, HURTREZ JE, DOMINGUEZ S AND MALAVIEILLE J. 2011. A new experimental material for modeling relief dynamics interactions between tectonics and surface processes. Tectonophysics 513(1-4): 68-87.

GRAVELEAU F, MALAVIEILLE J AND DOMINGUEZ S. 2012. Experimental modelling of orogenic wedges: A review. Tectonophysics 538-540: 1-66.

HUBBERT MK. 1937. Theory of scale models as applied to the study of geologic structures. Geol Soc Am Bull 48: 1459-1520.

KONSTANTINOVSKAYA E AND MALAVIEILLE J. 2011. Thrust wedges with décollement levels and syntectonic erosion: a view from analogue models. Tectonophysics 502(3-4): 336-350.

KOYI H. 1997. Analogue modeling: from a qualitative to a quantitative technique - A historical outline. J Petrol Geol 20(2): 223-238.

KOYI HA AND TEIXELL A. 1999. Where is the footwall flat? A cautionary note on template constraints. J Struct Geol 21: 373-377.

LIU H, MCCLAY KR AND POWELL D. 1992. Physical models of thrust wedges. In: McClay KR (Ed), Thrust Tectonics. Chapman and Hall, London, p. 71-81.

LOHRMANN J, KUKOWSKI N, ADAM J AND ONCKEN O. 2003. The impact of analogue material properties on the geometry, kinematics and dynamics of convergent sand wedges. J Struct Geol 25: 1691-1711.

MAILLOT B. 2013. A sedimentation device to produce uniform sand packs. Tectonophysics 593: 85-94.

MALAVIEILLE J. 2010. Impact of erosion, sedimentation, and structural heritage on the structure and kinematics of orogenic wedges: analog models and case studies. GSA Today 20(1): 4-10.

MASSOLI D, KOYI HA AND BARCHI MR. 2006. Structural evolution of a fold and thrust belt generated by multiple décollements: analogue models and natural examples from the Northern Apennines (Italy). J Struct Geol 28(2): 185199.

MULUGETA G. 1988. Modelling the geometry of Coulomb thrust wedges. J Struct Geol 10(8): 847-859. 
NILFOUROUSHAN F, PYSKLYWEC R AND CRUDEN A. 2012. Sensitivity analysis of numerical scaled models of fold-and-thrust belts to granular material cohesion variation and comparison with analog experiments. Tectonophysics 526-529: 196-206.

PANIEN M, SCHREURS G AND PFIFFNER A. 2005. Sandbox experiments on basin inversion: testing the influence of basin orientation and basin fill. J Struct Geol 27: 433-445.

PANIEN M, SCHREURS G AND PFIFFNER A. 2006 a. Mechanical behavior of granular materials used in analogue modeling: insights from grain characterization, ring-shear tests and analogue experiments. J Struct Geol 28: 1710-1724.

PANIEN M, SCHREURS G AND PFIFFNER A. 2006 b. Inversion of a symmetric basin: insights from a comparison between analogue and numerical experiments. In: Buiter SJH and Schreurs G (Eds), Analogue and numerical modelling of crustal-scale processes. Geol Soc of London, Special Publication 253: 253-270.

POWERS MC. 1953. A new roundness scale for sedimentary particles. J Sediment Petrol 23: 117-119.

RAMBERG H. 1981. Gravity, Deformation and the Earth's Crust. Academic Press, New York.

RAVAGLIA A, SENO S, TOSCANI G AND FANTONI R. 2006. Mesozoic extension controlling the Southern Alps thrust front geometry under the Po Plain, Italy: Insights from sandbox models. J Struct Geol 28: 2084-2096.

ROSSI D AND STORTI F. 2003. New artificial granular materials for analogue laboratory experiments: aluminium and silicious microspheres. J Struct Geol 25: 1893-1899.

RUTTER EH. 1986. On the nomenclature of mode of failure transition in rocks. Tectonophysics 122: 381-387.
SCHREURS G ET AL. 2006. Analogue benchmarks of shortening and extension experiments. In: Buiter $\mathrm{SJH}$ and Schreurs G (Eds), Analogue and numerical modelling of crustal-scale processes. Geol Soc of London, Special Publication 253: 1-27.

SCHULZE D. 1994. Development and application of a novel ring shear tester. Aufbereitungstechnik 35: 524-535.

SEPEHR M, COSGROVE J AND MOIENI M. 2006. The impact of cover rock rheology on the style of folding in the Zagros fold-thrust belt. Tectonophysics 427: 265-281.

TEIXELL A AND KOYI HA. 2003. Experimental and field study of the effects of lithological contrasts on thrustrelated deformation. Tectonics 22(5): 1054.

TURRINI C, RAVAGLIA AS AND PEROTTI CR. 2001. Compressional structures in a multilayered mechanical stratigraphy: insights from sandbox modelling with threedimensional variations in basal geometry and friction. In: Koyi HA and Mancktelow NS (Eds), Tectonic Modeling: A Volume in Honor of Hans Ramberg. Geol Soc Am Mem, Boulder, Colorado, p. 153-178.

VAN GENT HW, HOLLAND M, URAI JL AND LOOSVELD R. 2010. Evolution of fault zones in carbonates with mechanical stratigraphy - Insights from scale models using layered cohesive powder. J Struct Geol 32: 1375 1391.

WITHJACK MO, SCHLISCHE RW AND HENZA AA. 2007. Scaled Experimental Models of Extension: Dry Sand vs. Wet Clay. Houston Geol Soc Bull 49(8): 31-49.

YAMADA Y, BABA K AND MATSUOKA T. 2006. Analogue and numerical modelling of accretionary prisms with a décollement in sediments. In: Buiter SJH and Schreurs G (Eds), Analogue and numerical modelling of crustal-scale processes. Geol Soc of London, Special Publications 253: 169-183. 
